\title{
Estudio iconográfico de las grisallas del lienzo sur de la Capilla de la Soledad en la iglesia de San Sebastián de Soreasu, Azpeitia. Fuentes gráficas
}

\author{
Miren De Miguel Lesaca \\ Universidad del País Vasco
}

\begin{abstract}
RESUMEN. En este trabajo se analizan y se estudian por primera vez las pinturas renacentistas de la Capilla de la Soledad de Azpeitia, su iconografía parcial en lo que al lienzo sur compete, así como la figura del promotor y las motivaciones de dicha empresa. Se trata del conjunto de mayor interés iconográfico documentado hasta la fecha en Guipúzcoa, además del más claro exponente de la corriente renacentista, en lo que a sus modalidades arquitectónicas, escultóricas y pictóricas se refiere, un conjunto de un gran atrevimiento y modernidad, adalid de las enseñanzas y prácticas de los dictados del siglo XVI.

Palabras clave: pintura mural. Renacimiento. Azpeitia (Guipúzcoa). “Il Sogno”. Miguel Ángel.
\end{abstract}

ABSTRACT. In this work, the paintings of the Chapel of the Solitude of Azpeitia are analyzed and studied for first time, their partial iconography regardind to the south wall, as well as the figure of the promotor and the motivations for such a venture. It's the collection with the greatest iconographical interest documented until the date in Guipúzcoa, besides the more clear index of the Renaissance current, regarding to their architectural, scuptural and pictorial modes, a group of a great audacity and modernity, leader of the teachings and practical of the dictations of the XVI century.

Key words: Wall painting. Renaissance. Azpeitia (Guipúzcoa). "Il Sogno". Michelangelo.

\section{HALLAZGO DE LAS GRISALLAS DE LA CAPILLA DE LA SOLEDAD}

En el año 2002, la iglesia parroquial de San Sebastián de Soreasu accedió a las ayudas convocadas por la Diputación Foral de Guipúzcoa para la rehabilitación de las infraestructuras de la Capilla de la Soledad. La retirada del retablo que presidía la capilla dejó al descubierto parte de unas pinturas que asemejaban un Juicio Final. Desde el Taller de Restauración de la Diputación se procedió a las labores de localización de posibles zonas de policromía y la valoración del alcance de la misma. Las catas de limpieza dejaron al descubierto una extensa superficie pincelada bajo el estrato de policromía del XIX, que si bien no alcanzaba la totalidad de los muros (debido a fatales actuaciones, como la apertura de un nicho), cubría casi por completo los lienzos de la capilla. Actualmente, tras la restauración global finalizada en el 2006, las grisallas 
renacentistas lucen en su plenitud, en la capilla, bajo coro, coro superior y sacristía ${ }^{1}$.

El hallazgo y restauración de estas pinturas adquiere gran relevancia, teniendo en cuenta que se trata del conjunto funerario renacentista más completo de todo el territorio guipuzcoano y vasco, además de un gran exponente del renacimiento a nivel del territorio español. Y se trata sin lugar a dudas del conjunto de mayor interés iconográfico documentado hasta la fecha en Guipúzcoa. Hay que subrayar que el caso de la Capilla de la Soledad no tiene parangón en Guipúzcoa ni en el País Vasco. Es una obra excepcional en la que las pinturas han llegado hasta nuestros días en un excelente estado de conservación, ocupan un lugar preponderante en la lectura y significación de la estancia funeraria, y son el reflejo de las aspiraciones del promotor de la misma, claro exponente del pensamiento humanista. Cierto es que no es el primer caso en el que una intervención de tal índole deja al descubierto pinturas de épocas precedentes, pero son escasísimos los vestigios de pintura renacentista conservada en Guipúzcoa. Se conocen los casos del retablo fingido de Larraul, el retablo de San Francisco en Arrasate, la Anunciación de Lezo, los paños de Elgeta, San Pedro de Elgoibar, las pinturas de Itziar, y las claves de Santa Marina de Oxirondo de Bergara. Recientemente han quedado al descubierto pinturas renacentistas en el claustro de San Telmo en San Sebastián, cuya restauración finalizó en enero de 2010. Se abrirán al público en años venideros.

\footnotetext{
${ }^{1}$ El presente artículo es parte de un trabajo de investigación realizado bajo la dirección de la catedrática de Historia del Arte en la Universidad del País Vasco, Dulce Ocón Alonso, "Estudio histórico-artístico e iconográfico de la Capilla de la Soledad de la Parroquia de San Sebastián de Soreasu de Azpeitia", y presentado en 2007 en dicha universidad para la obtención del Diploma de Estudios Avanzados.
}

Si bien la Capilla de la Soledad no fue probablemente en su momento un caso único y excepcional en Guipúzcoa en cuanto a pintura se refiere, en la actualidad, por la inexistencia de otros modelos similares, por la pérdida de los mismos o bien porque están todavía ocultos bajo capas de enlucidos, sorprende la visión del interior de la capilla. Dada la gran calidad artística y la monumentalidad de su programa y de su factura, bien podemos tasarla de obra excepcional. Por encima de cualquier valoración personal, esta obra tiene todo el mérito añadido de ser una capilla totalmente renacentista, con arquitectura, escultura y pintura del renacimiento. $Y$ es este factor junto con su enorme calidad lo que le confiere el calificativo de obra maestra. Así, la complejidad del conjunto del mensaje de la capilla hace pensar en la preparación y el conocimiento de grabados y de significados que debió tener el artífice de la misma, y hace hincapié en el atrevimiento de la decoración y pinceladura, toda al romano. Se desconocen los nombres del pintor y de la persona que ideó semejante puzzle de figuras, mensajes y significados, pero cabe preguntarse sobre la formación de la misma o mismas. ¿En qué círculos se movió quien ideó el plan que habrían de seguir las grisallas de Azpeitia? ¿En qué otras obras trabajó? ¿Cómo y a quién se debe que en un lugar, en teoría, tan cerrado como Guipúzcoa a influencias renacentistas, tengamos una obra tan excelsa y que reúna tanto conocimiento sobre los idearios y modelos del Renacimiento?

Finalmente, hay que dar al lienzo sur la importancia que merece en el conjunto de las pinturas. El lienzo sur es la pieza clave de la capilla. Como lugar de enterramiento que es, y con el sentido funerario que ello implica, la vida y la muerte cobran sentido en dicha pared. Así, el juicio y el mensaje que se nos muestran serán la llave en el proceso de la muerte y resurrección del cuerpo y alma humana. 


\section{NICOLÁS SÁEZ DE ELOLA, IN- TRÉPIDO CAPITÁN DEL PERÚ}

Con el descubrimiento en 1492 de un nuevo continente, se abrió una etapa de conquistas que atrajeron hacia sí a hombres cuyas identidades y hazañas han quedado registradas en los anales de la historia, así como gentes anónimas que decidieron embarcarse, empujadas por diferentes motivaciones, a la aventura de las recién descubiertas américas. Uno de estos intrépidos aventureros fue Nicolás Sáez de Elola, hijo ilustre de Azpeitia, que participó activamente a las órdenes de Pizarro en la conquista del Perú, tal y como rezaba el cartel que ha presidido la capilla hasta su reciente restauración. El suyo es uno de esos casos con final feliz en el que el protagonista regresa a su Azpeitia natal colmado de unas riquezas que le permitirían en un futuro disponer de un lugar privilegiado dentro de la iglesia de San Sebastián de Soreasu, donde erigirse una capilla para el día de sus honras y misas póstumas.

Son escasos los datos que se conocen sobre la figura histórica de Nicolás Sáez de Elola ${ }^{2}$. Por las fechas que acontecen en diferentes documentos de la época, se podría situar su fecha de nacimiento a comienzos del s. XVI. Natural de la villa de Azpeitia en Guipúzcoa, era hijo legítimo de D. Joan

\section{-}

${ }^{2}$ El documento que arroja mayor luz sobre su figura es el testamento que se conserva en el Archivo del Ayuntamiento de Azkoitia. 1553/12/14 -1553/12/14. “Testamento de Nicolás Sáez de Elola vecino de la villa de Azpeitia en que entre otras cosas funda varias capellanías y obras pías en dicha villa nombrando por patrono de ella a la dicha villa de Azpeitia, y en caso de no cumplir las claúsulas de este testamento manda suceda en el patronato el regimiento de esta villa de Azcoitia. Otorgose en Azpeitia, a 14 de diciembre de 1553 ante Juan de Aquemendi". Papeles indiferentes sobre varios asuntos. Leg. $25, \mathrm{n}^{\circ}$ 6. Los datos que se aportan en este estudio son el resultado de la lectura e interpretación personal de los documentos, testamento, pleitos, cartas de pago u obligaciones que se conocen con relación a Elola.
Sánchez y Dña. Domeña Izarraga. Estaba casado con Dña. Ana Vélez de Alzaga y Vicuña y tenía una hija natural, llamada Francisca de Elola. Está asimismo documentada la existencia de un hermano, Joan Sáez de Elola, y familiares cercanos, tales como María Sánchez de Elola y Joan Sayz de Goyaz, primo. María de Idiaquez, citada en el testamento, podría ser tía de Francis$\mathrm{ca}^{3}$.

De la lectura del testamento se desprende que como fortuna personal antes de la aventura americana, Nicolás Sáez de Elola únicamente habría de percibir la legítima de sus progenitores, y en ningún momento se menciona siquiera la existencia de un solar adscrito al apellido paterno. Es de suponer que Joan Sáez de Elola fuera el hermano primogénito que habría de quedarse con la casa familiar, por lo que el menor debería probar fortuna en otras lides. Eso sí, Nicolás sabía leer y escribir, ya que el testamento cita que él mismo llevaba las cuentas de su ganado y sus caserías.

Se desconocen a ciencia cierta las directrices de su existencia antes de la aventura del Perú, pero se sabe que fue capitán a las órdenes de Pizarro, y se sobreentiende que su participación en la conquista supuso un antes y un después en su vida. No hay lugar a dudas de que el oro americano le permitió construirse su propio solar ${ }^{4} \mathrm{y}$ lo

-

${ }^{3}$ J. I. LASA, Tejiendo historia. Contribución a la pequeña historia de Guipúzcoa, Donostia, 1977, p. 117. Esta María de Idiaquez era la persona responsable de que se cumpliera lo estipulado por Nicolás de Elola en su testamento, en relación con el casamiento de su hija con el pretendiente que escogiera dicha María de Idiaquez.

4 Archivo del Ayuntamiento de Azkoitia. 1553/12/14 -1553/12/14. Testamento de Nicolás Sáez de Elola. A lo largo del testamento se recoge que la casa en la que Nicolás residía al momento de la redacción de sus últimas voluntades no era la misma en la que nació, y que la misma había sido construida con su propio esfuerzo. “(...) donde el d(ic)ho Nicolas/ Sanches nascio $\mathrm{q}(\mathrm{ue})$ es en la $\mathrm{d}(\mathrm{ic})$ ha Villa e non de la casa 
más importante aún, ligar su apellido a la iglesia parroquial de Azpeitia, que actualmente luce con orgullo la presencia del mausoleo de Elola. Parece que este mismo oro americano le supuso un ventajoso matrimonio con Ana Vélez de Alzaga y Vicuña, descendiente de uno de los linajes más importantes e influyentes del contexto político de la época ${ }^{5}$. La que fuera señora de Elola percibió por el casamiento con el indiano 2000 ducados de oro del momento ${ }^{6}$, matrimonio que parecía roto un año antes de la redacción del testamento ${ }^{7}$. Aun así, la jugosa fortuna de Nicolás hizo que a su muerte se sucedieran los pleitos entre la mujer y el hermano Joan Sáez, heredero casi universal $^{8}$.

donde esta e reside al presente"(...) "Asi bien declaro $\mathrm{q}(\mathrm{ue})$ to(do) el axuar de la d(ic)ha casa donde vivia e/ moraba e por el fue edificada e puesto e pagada el coste della" (..) "Yten asi bien declaro el d(ic)ho Nicolas Sanches q(ue) el edifico e fa/brico a su costa la $\mathrm{d}(\mathrm{ic})$ ha casa e torre donde estaba".

${ }^{5}$ Parece que por vía materna, Ana Vélez de Alzaga y Vicuña fuera descendiente de la rama de los Loyola. Archivo de la Real Chancillería de Valladolid, ES. 47186.ARCHV/1.7.2//REGISTRO DE EJECUTORÍAS. CAJA 0377.0001. "María Juanes de Mendizabal con María de Vicuña, mujer de Juan de Alcega, vecinos de Azpeitia (Guipúzcoa), sobre la posesión de los bienes y herencia de Juan Pérez de Vicuña y María López de Loyola". Además, el solar de la casa y torre de los Vicuña se recoge varias veces en el testamento.

${ }^{6}$ Este dato aparece reflejado en el testamento, ya que recoge las disputas existentes entre los consortes, ya que hacía un año que el distanciamiento entre ambos era patente. "Otro si declaro q(ue) pago a la señora Doña Maria de Vicuña los dos myll du(cad)os de oro $\mathrm{q}(\mathrm{ue})$ prometio en dote al $\mathrm{t}(\mathrm{iem})$ po de su casami(ent)o".

${ }^{7}$ Archivo Diocesano de Pamplona. № 568, Azpeitia 1553. “ $D$ a Ana de Vicuña, señora de la casa solar de Vicuña, en Azpeitia, contra su marido Nicolás de Elola, pidiendo la separación matrimonial, a causa de las sevicias y malos tratos de que fue objeto por parte de su marido, al que acusa también de adulterio. Se concede la separación, mandando a Elola pagar medio ducado diario a su mujer y devolverle la dote. Secr. Cascante C/34, no 12 .

${ }^{8}$ Archivo de la Real Chancillería de Valladolid. 1554/01/01 -1554/12/31. Valladolid. “Ana Vélez de
En el año 1537, el que se conociera como Nicolás de Azpeitia en su aventura americana ya se encontraba de regreso en su Azpeitia natal. Parece que tras la conquista del Perú, el capitán regresó a casa antes de que estallaran los enfrentamientos entre los partidarios de Almagro y de Pizarro. Trajo consigo una ingente fortuna, una india del Perú ${ }^{9}$, un pleito con Juan Rojas de Solís por un cántaro de plata ${ }^{10}, \mathrm{y}$ más importante aún, un privilegio real otorgado en Sevilla, mediante el cual el dicho Nicolás percibiría anualmente y de forma perpetua 300.000 maravedíes $^{11}$.

A su regreso, Elola fundó una serie de obras pías ${ }^{12}$ para mayor gloria de su figura. Fuera como fuese hombre de vida militar y de negocios, los escasos artículos que tratan sobre su vida siempre citan su lado humanista, el dejar parte de su herencia a los más desfavorecidos de la villa, y el fundar su propia Cátedra de Gramática. Cierto es que existía a este respecto un ejemplo anterior en el tiempo. En el año 1540 había quedado inaugurada la Universidad de Oñate con su propia Cátedra de

Alzaga, viuda, pide a Juan de Elola, ambos vecinos de Azpeitia, le pague la mitad de los 5824 ducados que cobró en nombre de Nicolás Sáenz de Elola, difunto, su marido, que la corresponden como bienes gananciales". Pleitos Civiles. Escribanía Varela. Pleitos Olvidados. C 768/2. Olim: L 184.

${ }^{9}$ Archivo de Indias de Sevilla. INDIFERENTE, 423,L.18,F.61v-61bis-r. (23-11-1537)

${ }^{10}$ INDIFERENTE, 423,L.19,F.295r-295v. (24-10-1539).

11 Archivo General de Simancas. ES.47161.AGS/1.1.16.2.5//CME,98,6. "Juro a favor de Nicolás Sánchez de Elola de 300.000 maravedíes".

${ }^{12}$ Fundó ciertas capellanías, una cátedra de gramática, dejó por escrito la dote que habría que entregar anualmente para el casamiento de doncellas pobres, y estipuló una renta anual para su hija natural Francisca, la cual habría de tomar los hábitos en el convento de Bidaurreta o aceptar un matrimonio concertado. Archivo del Ayuntamiento de Azkoitia. 1553/12/14 1553/12/14. Testamento de Nicolás Sáez de Elola. 
Gramática ${ }^{13}$.

Pero la materialización suprema de su fortuna se tradujo en la construcción de la Capilla de la Soledad, última voluntad del indiano, que se inició al poco de la defunción del fundador y que ya en 1560 albergaba el mausoleo de Elola.

\section{IGLESIA PARROQUIAL DE SAN SEBASTIÁN DE SOREASU. CAPI- LLA DE LA SOLEDAD}

La iglesia parroquial de San Sebastián de Soreasu muestra capillas funerarias de los personajes más ilustres y pudientes de Azpeitia, de diversas épocas y estilos, tanto de corte gótico como renacentistas. Una de ellas destaca por encima de todas las demás, la Capilla de la Soledad, lugar de enterramiento de Nicolás Saez de Elola.

Su situación privilegiada de "semiindependencia" (actualmente se halla dentro del perímetro de la iglesia y su sacristía, pero en el momento de su edificación tuvo acceso desde el exterior, con portada policromada) y su extensión hacen de ella un magnífico expositor del pensamiento y de los anhelos de su fundador. Si bien el propio Nicolás Sáez de Elola compró el terreno en que se ubicaría su enterrorio, no dispuso los detalles de la edificación y remate de la misma ${ }^{14}$. Sin embargo, dejó por escrito el poder que transfería a sus albaceas, los alcaldes y regidores del concejo de Azpeitia ( $y$ en su defecto los de Azkoitia), quienes en

\footnotetext{
${ }^{13}$ M. A. ARrazola, El renacimiento en Guipúzcoa. Tomo I. Arquitectura, Donostia, 1988, p. 275, citando un documento del Archivo de la Universidad de Oñate, A.U.O. A, 3, 1, 2.

${ }^{14}$ Testamento. "Yten mando q(ue) en la $\mathrm{d}(\mathrm{ic}) \mathrm{ha}$ ygl(es)ia e parrochia de la d(ic)ha villa en la/ parte $\mathrm{d}(\mathrm{ic})$ ha donde tenya comprado el $\mathrm{d}$ (ic)ho Nicolas Sanches el sitio de la/ d(ic)ha capilla e esta señalado se hiziese una capilla $q(u e)$ el hedi/ficio della cueste hasta en quantia myll dozientos du(cad)os de/ oro e en la $d$ (ic)ha capilla se haga su sacristia e el sitio pa(ra) el hor/gano q(ue) ha de aver en ella".
}

primera instancia se habrían de preocupar de disponer de la construcción, decoración escultórica y pinceladura de la capilla, convirtiéndola en el mayor exponente renacentista que se conserva en Guipúzcoa.

En el año 1553 dichos albaceas convocaron un concurso en el que los principales canteros y arquitectos fueron invitados a presentar sus proyectos para la edificación y modificación del terreno que habría de convertirse en capilla. En subasta pública se concedió la realización de las obras a Domingo de Rezabal, maestro cantero. La propuesta mencionaba que la tierra y el sitio que iba a ocupar la capilla tendría de ancho catorce varas por quince varas de largo, lo que daba un total de doscientas tres varas. La sacristía tendría nueve pies de ancho y el grueso de las paredes se dispondría de la siguiente manera: la capilla cuatro pies de grosor y la sacristía tres y medio. ${ }^{15}$.

La entrada por la iglesia, "no de fueraparte", sería rematada con una puerta con reja de veinticuatro pies de alto hasta la mocheta del arco. Enfrente a la entrada habrían de ir el altar y retablo, y el enterramiento y el sepulcro en medio del arco, fijado y metido en la pared. En esta misma pared, habrían de abrirse dos ventanas redondas, con dos medallas en las que se representarían las figuras de San Pedro y San Pablo. El cimborrio vendría encima de cuatro arcos triunfales, y sobre ello, la linterna, que surtiría de luz suficiente la capilla. $\mathrm{Y}$ en las cuatro pechinas, labrados al natural, irían los cuatro evangelistas. Finalmente, del coro saldría el sitio para el órgano, asunto muy bien mirado para que este instrumento pudiera adornar con las voces.

\footnotetext{
${ }^{15}$ Para mayor detalle, consultar en el Archivo Histórico de Protocolos de Guipúzcoa, GPAH20009_A_0750r_A_0751v
} 
Una vez aceptada la propuesta de Rezabal, el concejo de la villa de Azpeitia pasó a dictar ciertas condiciones ${ }^{16}$. El documento GPAH20009_A_0764r_A_0765v, cita algunos puntos curiosos referentes a las condiciones constructivas y decorativas, que si bien en su mayoría se respetaron a pies juntillas, divergen en otros aspectos respecto a los dictámenes del concejo. “(...) Y será todo en todo estilo al Romano, puesta cada cosa en forma y medida según (...) de hombres artistas sin mezcla alguna con lo moderno (...) que no haya de poner escrúpulo alguno de por ello ser la obra falsa". Este primer dato resulta de una modernidad inusitada, si nos paramos a pensar en la rotundidad de la afirmación. Exceptuando los casos de la Universidad de Oñate y el convento de San Telmo en Donostia, no se conocían más exponente "romanos" en la zona y alrededores. Es sencillamente asombroso que con tan escasos precedentes en lo que a arquitectura renacentista se refiere, su capilla se dispusiera siguiendo unas clarísimas pautas en las que se desechaban por completo las soluciones góticas que tan profusamente se habían trabajado en el País Vasco ${ }^{17}$.

\section{-}

${ }^{16}$ Existen además diversos documentos referentes
a matizaciones del proyecto de Rezabal.
GPAH20009_A_0756v_A_0757r y GPAH20009_A_
0752r_A_0752v
${ }^{17}$ Se coincide en el hecho de que la recepción de los modelos renacentistas no tiene una respuesta homogénea en el País Vasco. Si bien las condiciones económicas que se vivieron en el s. XVI fueron favorables, hecho que haría prever una fiebre constructiva (por lo menos en lo que a espacios públicos se trata, iglesias etc.), no se refleja ni en la cantidad ni en la excesiva calidad. Algunos ejemplos se escapan como excepción, la Universidad de Oñati y la propia Capilla de la Soledad de Azpeitia. La representatividad del Renacimiento no queda a la altura del desarrollo tanto económico, como político y social. Sí es cierto que, en contraposición, el enriquecimiento individual y la bonanza económica colectiva trajo consigo la eclosión del caserío, tal y como lo concebimos actualmente. La prosperidad y sensación de seguridad que se vivió en el s. XVI hizo que los antiguos caseríos medievales dieran paso a edificaciones abiertas al exterior, con
A este párrafo se suman afirmaciones tales como "una sepultura y enterrorio dentro de la pared en entrando a la mano izquierda, todo al Romano (...) y así mismo el bulto de la persona de Nicolás se haga al propio perfecto y Romano". "Así mismo, haya de pintar y pincelar y lucir todo el cuerpo de dicha capilla (...) y todo esto se ha de hacer al fresco luego en la dicha opción se presente sin intervalo alguno con que sea de cal viva y manufactura de cera $y$ resina y leche de higuera y cola y otras mixturas necesarias para el dicho betún y labor". La técnica utilizada no fue el fresco, sino el temple, ya que la base de estas grisallas está constituida por negro a base de carbón vegetal, carbonato cálcico sobre mortero de cal, y realizadas "a seco".

Llegados al año 1557 se planteó que la edificación de la capilla no resultaba del agrado de los constructores y se acudió al obispado de Pamplona solicitando modificar el testamento del difunto. Se pidió gastar hasta 1000 ducados más, y ampliar el solar de construcción, ya que la capilla resultaba pequeña para tamaña villa ${ }^{18}$.

numerosas ventanas ricamente decoradas. El tema de la influencia y el arraigo del renacimiento en el País Vasco se estudia en J.A. BARRIO LOZA, «Paisaje aproximado de la arquitectura renacentista en el País Vasco», Revisión del arte del Renacimiento, Ondare, cuadernos de Artes Plásticas y Monumentales, Donostia, 1998, p.p. 33-56; I. CENDOYA ECAHANIZ, «Reflexiones en torno al arte del s. XVI en Gipuzkoa», Revisión del arte..., p.p. 157-166; F. MARÍAS, «El Renacimiento "a la castellana" en el País Vasco: concesiones locales y resistencias a "lo antiguo"», Revisión del arte..., p.p. 1731.

${ }^{18}$ Archivo Diocesano de Pamplona. Secr. Cascante, c/38, 1557. “(...) el fundador mando que en la obra de la dicha capilla se gastasen hasta mill y/ dozientos ducados. Despues de lo qual por que el edificio vernia muy pequeño para tan gran/ pueblo como es la dicha villa y su traça e por otros buenos respectos. Vuestra señoria manda/ y dio licencia que de los bienes del defuncto se gastasen hasta otros mill ducados/ que eran dos mill y dozientos agora vista la traça de la dicha capilla y el lugar/ do se edifica se tomaron para su anchura tres varas y media de suelo, e se saca/ron 
Superadas las dificultades y rematada la obra, su planta de cruz griega (prácticamente cuadrada), y su cúpula casetonada como elemento de cubrición, remiten a una edificación de corte puramente renacentista, y por ende, la joya de la iglesia parroquial de San Sebastián de Soreasu, en Azpeitia. Sus paredes se retranquean ligeramente respecto al eje central y cada uno de los lienzos se une al contiguo mediante paredes rematadas con arcos de medio punto casetonados. El cierre de la cúpula casetonada se remata en linterna. Pincelada en todos sus paramentos, la capilla es un compendio y un libro de manual del buen hacer renacentista, donde todas las disciplinas artísticas presentes, arquitectura, escultura y pintura, son totalmente coetáneas.

\section{GRISALLAS, UN PROGRAMA ICONOGRÁFICO LLENO DE VIR- TUOSISMO}

Que la virtud es la constante del mensaje de los pudientes renacentistas es algo que se respira en la capilla de la Soledad. Previamente ya se habían erigido en las proximidades de Azpeitia dos edificios que fueron precursores de estas ideas en el territorio guipuzcoano, la Universidad y el convento de Bidaurreta en Oñate. Rodrigo Mercado de Zuazola, responsable de la Universidad de Oñate, contó con el trabajo de Pierres Picart, quien dotó a la fachada de cuatro pilastrones cuyos vanos se decoraron con las imágenes de Hércules, santas y santos y personajes de virtud en general ${ }^{19}$.

Como anfitrión de la capilla, entrando a la misma desde el interior de la iglesia,

los cimientos del un lienço para hacer la mayor porque no vernia en cuadra(tura)/ ni en buena comodidad".

${ }^{19}$ El tema de la Universidad de Oñate ha sido estudiado por J.M GONZÁLEZ DE ZARATE \& M. J. RUIZ DEL AEL, Humanismo y arte en la Universidad de Oñate, Vitoria, 1989; M. FORNELLS ANGELATS, La Universidad de Oñati y el Renacimiento, Donostia, 1995. es el mismo Hércules, acompañado por Venus, quien da la bienvenida a los visitantes desde el arco carpanel en cuyo intradós se localiza. Ambos relieves (los únicos de la capilla) se refieren a la virtud, el primero, como hombre virtuoso y antecesor de la monarquía española, y la segunda como la verdad y la humanidad. Las grisallas de la templanza y la Virgen Protectora se ubican a los lados de estos personajes mitológicos recuperados en el Renacimiento. La Templanza, como virtud cardinal que es, ataviada y tocada a la manera clásica y acompañada por dos jarras, hace honor a la moderación, quietud y equilibrio y la Virgen y el Niño amparan y acogen en su seno a los visitantes, mientras flanquean la puerta a la sacristía y la subida al coro.

Son muchos los elementos que hacen clara referencia a la virtud, característica tan codiciada para el humanismo del XVI. Dentro de la capilla, tres grandiosos paños relatan la lucha entre lo correcto y lo incorrecto, la virtud y los vicios y pecados (la sacristía también participa de este mensaje) como muestrario didáctico del pensamiento humanista y religioso. Elola, dignamente ataviado en su sepulcro, duerme y descansa plácidamente, esperando la Resurrección de la carne, a sabiendas de que su vasto programa iconográfico es claro reflejo de la virtud, la fama y la gloria, que han sido sus directrices en la conquista del Perú y en el regreso a su Azpeitia natal. El mausoleo resulta una especie de "retablo" en el que se recuestan dos figuras femeninas talladas en piedra, más otras dos pinceladas. Se trata de la Virtud (las esculturas sujetan un cartel que muestra la palabra Birtus), y posiblemente la Gloria, la fama y el reconocimiento a una vida de grandes hazañas. Es justamente esta vida militar la que se muestra pincelada y enmarcada en una especie de arco de triunfo. Elola sobre su cabalgadura, pisa una esfera terrestre, sobre un fondo de lanceros y portaestandartes (Fig. 1). 
La Caridad del lienzo Este, representada en la figura de una mujer que ampara un grupo de niños, sigue corroborando cada una de las ideas expuestas. El amor hacia el prójimo y hacia Cristo se hace tangible en este lateral. Es necesario participar de la Caridad para poder disfrutar del acercamiento a la divinidad y remontarse tan alto como lo hace la Gloria. Recordemos que Elola en su testamento puntualizó sobre el reparto de parte de su fortuna a los desfavorecidos de la villa.

\section{LIENZO SUR. DESCRIPCIÓN DE LAS GRISALLAS}

El paño Sur es quizá el más espectacular por ser el único que está íntegramente pincelado (sin ningún tipo de decoración escultórica), y por la enorme calidad de sus pinturas. La composición de las grisallas está dividida en dos, de manera que la parte superior queda enmarcada por un arco de medio punto y la parte inferior se inserta dentro de una moldura geométrica fingida, por debajo de la línea de imposta. Como nexo de unión, dos ángeles trompeteros, simétricamente dispuestos, rompen con dicha división espacial y dotan a la escena de mayor dinamismo (Fig. 2).

La parte superior nos habla de la Visión de Ezequiel $^{20}$, profeta mayor que vivió como cautivo en Tell-Abib. En el quinto año de su cautiverio por tierras de Babilonia (594-593), Dios lo eligió como su profeta para que durante 22 años exhortase e incitase a penitencia a los judíos, que abandonando el culto divino, habían caído en la idolatría y vicios de los vencedores babilonios.

A la izquierda se sitúa el tetramorfos, rodeado de montones de nubes. En el punto central, se representa el Padre Eterno,

\footnotetext{
${ }^{20}$ SAGRADA BiBlia, Buenos Aires, 1958, Ezequiel I, $1,4,5,510,11,15,16,26-28$.
}

que rige el mundo con el cetro en la mano izquierda y la esfera en la derecha. Sentado sobre un arco y con nubes a sus pies, Dios Padre se rodea de una aureola de haces de luz. El recorrido lógico desemboca en la imagen de dos ruedas entrelazadas entre sí. También éstas vienen acompañadas con un grupo de nubes, que son las responsables de albergar a los ángeles trompeteros.

Tal y como Ezequiel relata en su visión, entre una ebullición de nubes, torbellinos de viento y fuego, se le aparece la imagen de un personaje, el Padre Eterno en majestad, sentado sobre su trono en forma de arco iris, enmarcado en una especie de resplandor con forma almendrada del que salen rayos de luz que intensifican la ya de por sí resplandeciente aparición de la figu$\mathrm{ra}^{21}$. Con su mano derecha sujeta una esfera, (como creador del mundo), y en la izquierda blande un cetro ${ }^{22}$. Los dos elementos son en justicia los representantes del alcance de su poder.

La visión del que está sentado en el trono se representa con los rasgos de un venerable anciano, con barba y pelo largos, y con tiara de tres coronas en la cabeza, aludiendo a la Trinidad. Viste una túnica que cubre todo su cuerpo, y una capa anudada al cuello que cae por sus hombros. A la izquierda, el tetramorfos difiere de la descripción que de él hace Ezequiel. Si bien en la visión cada uno de los animales tenía cuatro cabezas ${ }^{23}$, siendo cada una de ellas de hombre, águila, buey y león, la complejidad de la escena propició la simplificación de la misma. Lo mismo sucede con las alas, que se reducen y se simplifican, estableciéndose un único par, representación que se mantendrá hasta el Apocalipsis de San

\footnotetext{
${ }^{21}$ Esta visión de Dios entre nubes también la recogerá posteriormente San Juan, Apocalipsis I, 7; IV, 2-3

22 "Y os someteré a mi cetro, y os haré entrar en los lazos de mi alianza", Ezequiel XX, 37.

${ }^{23}$ EZEQUIEL I, 6.
} 
Juan del Nuevo Testamento ${ }^{24}$. Y ya a partir de la interpretación de San Ireneo, los cuatro animales pasarán a asimilarse con las representaciones de los cuatro evangelistas del Nuevo Testamento.

Respecto a las dos ruedas entrelazadas, "asimismo las ruedas tenían tal circunferencia y altura, que causaba espanto el verlas; y toda la circunferencia de todas las cuatro estaba llena de ojos por todas partes" ${ }^{\prime 25}$. Es de mencionar que en las grisallas de Azpeitia, los ojos de la circunferencia de las ruedas se han desvirtuado y que en vez de ojos, lo que se aprecian son una especie de huecos o hendiduras. Sigue diciendo, "y a estas ruedas oí yo que les dio el nombre de volubles o "ligeras" ${ }^{\text {"26 }}$, que pudieran hacer alusión al mensaje de la universalidad de la presencia divina, es decir, la capacidad de omnipresencia de $\mathrm{Cristo}^{27}$. Y la doble rueda de Ezequiel es el símbolo de los dos Testamentos y de su relación indisolu$\mathrm{ble}^{28}$.

No cabe duda de que el sentido global de la visión de Ezequiel es la idea general del Juicio. No llega a tener el alcance del Juicio Universal o Final, pero en él se trata la necesidad de inculcar valores de obediencia y rectitud en los hombres, ya que serán juzgados por sus acciones y castigados o recompensados en consecuencia.

${ }^{24}$ APOCALIPSIS IV, 7.

${ }^{25}$ EZEQUIEL, I, 18.

${ }^{26}$ EZEQUIEL, X, 13.

${ }^{27}$ J. F. ESTEBAN LORENTE, Tratado de iconografía, Madrid, 1992, p. 511-512.

${ }^{28}$ J. HERVELLA VÁZQUEZ, «Ezequiel en la Historia del Arte, en la literatura y en la emblemática», Reseña Bíblica, Ezequiel, Estella, № 52, 2006, p. 42; L. REAU, Iconografía del arte cristiano. Antiguo testamento, Barcelona, 2000, p. 431; SAN JERÓNIMO, Obras completas, Comentario a Ezequiel. Libro I., Madrid, 2000, p. p. 29, 35. Esta visión de Ezequiel es la antesala de la visión apocalíptica de San Juan, y ambas contienen similar mensaje.
La parte inferior del lienzo sur está modificado con respecto a la obra del siglo XVI. Como se ha citado en páginas anteriores, la Capilla de la Soledad fue en su totalidad remodelada estéticamente en 1898, año en que las actuales pinturas renacentistas recibieron una repolicromía acorde con los gustos decimonónicos. A mitad de altura, José Manuel de Larrar abrió un nicho para contener en él la figura de la Flagelación de Cristo. Con la restauración de la Capilla el agujero correspondiente al nicho se rellenó y se reintegró con un color de tonalidad inferior a las grisallas.

Toda la parte circundante, sin embargo, se conserva en muy buen estado. La composición se articula alrededor de una figura central de la que únicamente quedan las piernas, dispuestas de forma que la pierna derecha se pliega y se apoya en una especie de caja rectangular, y la izquierda cae hasta el suelo. Esta caja, que parece hueca (su frente simula una perspectiva), se cubre en parte con un paño sobre el que descansa una esfera. A los lados, grupos de personas desarrollan diferentes actividades, ordenados, clasificados y separados por arquitecturas dibujadas o nubes que los delimitan.

Siguiendo un orden ascendente desde la parte inferior izquierda, en el sentido de las agujas del reloj, el grupo situado en la parte inferior lo forman un hombre con los brazos cruzados, cabeza gacha y mirada perdida o de hastío, y un segundo hombre que sujeta entre sus manos un odre o bota de vino que se lleva a la boca. El segundo grupo se compone de un hombre que parece apoyarse en otra mesa, mientras que con el brazo derecho se atusa la barba con la mirada perdida en el infinito. Debajo, una figura mira de frente y justo por encima de los dos anteriores, otro personaje se lleva la mano a la boca en gesto de silencio o asombro, con la mirada asustada o desorbitada. 
El tercer grupo de la mitad izquierda es uno de los grupos más claros. Son dos hombres que se abrazan y se besan. Un tercero aparece en el ángulo superior izquierdo, con los brazos en alto y sujetando algo parecido a unos cortinajes. A su derecha se halla el grupo que mayor cantidad de personas acumula. Como figura principal, un hombre tocado con cuernos y provisto de un palo o lanza que blande con el brazo derecho, bien armado. Con el brazo izquierdo, sujeta la capa del hombre que se sitúa más a la derecha, cuyo único atributo es el propio trozo de tela con el que se tapa. En el hueco que queda entre ambas figuras, bajo el brazo izquierdo del personaje con cuernos, se aprecia una cara "flotando". Y por último, un hombre cierra la composición en la parte izquierda de la escena. No se conserva más que su cara y cuello, por lo que se desconoce si en el momento de su creación estaba desempeñando alguna acción.

Por último, el grupo de la parte inferior derecha se compone de tres personajes. Un hombre barbudo aparece sentado, con el brazo derecho alzado, con las piernas cruzadas y girado sobre su propio eje. A sus espaldas, una figura alza sus manos en gesto de asombro y una tercera persona, sujeta una escalera.

\section{FUENTES GRÁFICAS. VISIÓN DE EZEQUIEL. HANS HOLBEIN EL JOVEN}

Que el grabado fue la fuente de inspiración de numerosos artistas de primer $\mathrm{y}$ segundo orden, es un hecho totalmente probado. En el siglo XVI, el grabado se convirtió en un sistema de reproducción rápido, barato, de múltiples copias, y sobre todo, de fácil movilidad de las mismas. Es un método de reproducción de obras ajenas, de dar a conocer las mismas a falta de la contemplación del original, y en un sentido más amplio, de exportarlas fuera de las fronteras y los límites en que fueron creadas.

Las relaciones que España mantuvo con Flandes con respecto al tráfico comercial, además de las alianzas matrimoniales reales y la tendencia de Carlos V y sus consejeros hacia tierras flamencas, fueron determinantes para que las primeras décadas del siglo XVI fueran un constante ir y venir de obras de arte flamencas. También el arte que se estaba haciendo en Italia tuvo su reflejo dentro de España ${ }^{29}$. Pero fue a partir del segundo tercio del siglo XVI, cuando comenzaron a importarse en grandes cantidades los grabados de genios italianos como Rafael, Miguel Ángel y artistas extranjeros que desarrollaron su trabajo en este país $^{30}$, grabados que convivieron con los flamencos. Atendiendo a estudios de Echeverría, los modelos pictóricos de que se sirvieron para pincelar los muros de las diversas edificaciones del País Vasco, provenían de grabados nórdicos e italianos, aunque parece que el predominio de los primeros frente a los segundos es palpa$b^{3} e^{31}$. Y la Capilla de la Soledad no fue ajena a tales influencias.

${ }^{29}$ J. YARZA LUACES, Los reyes católicos. Paisaje artístico de una monarquía, Madrid, 1993. "Son los años en los que dos grandes modelos artísticos, el italiano y el nórdico, principalmente gestado en los Países Bajos, adquieren su formulación definitiva, antes el segundo que el primero", p.369.

${ }^{30}$ Ma P. SILVA MAROTO, «La utilización del grabado por los pintores españoles del siglo XVI», Jornadas Nacionales sobre el Renacimiento Español, Príncipe de Viana, Pamplona, 1991, p. p. 316-317. La autora recoge que en el último tercio del siglo XVI, pintores y mercaderes italianos residentes en España distribuyeron en Barcelona un lote de 3500 grabados procedentes de Roma. Y en Sevilla, los inventarios existentes dan prueba de que los grabados que llegaban a su puerto se quedaban por tierras andaluzas.

${ }^{31}$ P. L. ECHEVERRÍA GOÑI, «Contribución del País Vasco a las artes pictóricas del Renacimiento: la pinceladura norteña», Revisión del arte del Renacimiento, Ondare, cuadernos de Artes Plásticas y Monumentales, Donostia, 1998. Para la exposición de esta teoría 
Así, la Visión de Ezequiel de la parte superior del lienzo sur está basada en el grabado que ideó Hans Holbein el Joven para una ilustración homónima y que fue editada en Lyon en 1543 en un libro titulado "Retratos o tablas de las historias del Testamento Viejo, hechas y dibuxadas por un primo y sotil artífice. Igualmente con una muy breve y clara exposicion y declaracion de cada una dellas en Latin, con las quotas de los lugares de la Sagrada Scritura de donde se tomaron, y la mesma en lengua Castellana, para que todos gozen dellas" ${ }^{132}$ (Fig. 3). El grabado venía acompañado por un texto en latín en la parte superior y una quintilla castellana en la inferior. La primera dice así: "Ezechielis quatuor animalium, rota/rum, throni \& imaginis super thronum vi/sionis". La parte inferior dice esto otro: "Animales muy temidos/ vio en vision Ezechiel/ de un carro muy asidos/ y de cerca el trono metidos/ donde esta Dios de Israel". Fue concebido, junto a un variado número de grabados, como parte de una serie de ilustraciones del Antiguo Testamento. Y como se comprueba, el grabado se ha reproducido con exactitud y fidelidad, sin modificaciones respecto al original.

\section{IL SOGNO}

El hecho de localizar la fuente gráfica de la Visión de Ezequiel, pone en relieve la importancia de la difusión de grabados en

apunta a la referencia bibliográfica de I. MATEO GOMEZ: Panorama de la pintura europea del Renacimiento e influencia del grabado alemán en España; Véase además, J. CARRETE PARRONDO, «El grabado vasco-navarro en el Renacimiento», Revisión del arte..., p.p. 107-112; R. SAENZ PASCUAL, «La influencia del grabado en la pintura manierista: el ejemplo de las tablas de Añes (Álava)", Revisión del arte..., p.p. 447-452; X. CASTAÑER, Pinturas y pintores flamencos, holandeses y alemanes en el Museo de Bellas Artes de Bilbao, Bilbao, 1995, p. 10. En esta misma dirección apunta el estudio de las relaciones artísticas y comerciales entre Bilbao, Flandes y Holanda en el siglo XVI.

${ }^{32}$ H. Holbein. Imágenes del Antiguo Testamento, Illes Balears, 2001.
Guipúzcoa, así como la utilización de modelos gráficos nórdicos como base para programas iconográficos. Habiendo localizado el primer grabado, era lícito pensar que en el curso de la investigación se pudieran identificar más fuentes gráficas en las que estuvieran basadas las pinturas. $Y$ así sucedió con el Il Sogno, obra que Miguel Ángel realizara hacia 1533 (Fig. 4).

Desde un comienzo, el dibujo de Miguel Ángel nació como un regalo personal para Tomasso Cavalieri y Vittoria Colo$\mathrm{na}^{33}$. A grandes rasgos y fijándonos en el título que se dio al dibujo, la obra trataría sobre el sueño, el sueño de la vida humana. Se entiende por sueño, un viaje a la inconsciencia, a lo irracional, al mundo no regido por la mente. Es en este viaje en el que comienzan a desfilar los vicios y pecados, en el momento en el que la mente se ha liberado de la rectitud moral de la conciencia. En líneas generales, Il Sogno representaría una alegoría moral, un discurso didáctico que pretendería enseñar los diversos caminos que el hombre puede tomar, el de una vida de compromiso moral, o el camino del pecado y del disfrute exacerbado de los sentidos. Parece ser que esta última interpretación proviene del siglo XVII, cuando Hieronymus Tetius visitó el Palacio Barberini y contempló la obra de Miguel Ángel ${ }^{34}$. Tetius interpretó la figura central del hombre como el alma humana y la figura alada con trompeta como el ángel responsable de despertar el alma humana.

El sueño que en la mitología griega se asimila con Hypnos, hermano de Thana-

33 P. L. DE VECCHI, Michelangelo Pittore, Milan, 1984; P. PREISS, Miguel Ángel. Dibujos, Barcelona, 1982; M. RUVOLDT, «Michelangelo's dream», Art Bulletin, New York, p.p. 86-113; M. WINNER, «Michelangelo's Il Sogno as an Example of an Artist's Visual Reflection in His Drawings», in Michelangelo Drawings, Studies in the History of art, vol. 33, p.p. 227-239.

${ }^{34}$ M. RUVOLDT, op. cit, p. 86, M. WINNER, op. cit, p. 228. 
tos (Muerte) e hijo de la Noche, es el responsable del descanso nocturno y de las pesadillas y malos pensamientos. Pero el sueño también ha sido considerado premonitorio, ya que dirigentes militares y políticos entre otros, han conocido los avatares del futuro mediante la interpretación de los sueños.

En la actualidad está muy extendida la idea de que el dibujo encierra un mensaje que el propio Miguel Ángel quiso plasmar para el receptor del regalo, ya que según parece, el genio florentino sentía un amor platónico hacia Cavalieri ${ }^{35}$. Sus creencias neoplatónicas aborrecían y rechazaban ese sentimiento, de forma que el autor se castigaba y atormentaba a sí mismo representando al joven de la parte central rodeado de vicios, tal y como él concebía su situación personal. Para corroborar esta teoría, los autores se basan en la correspondencia privada entre Miguel Ángel y Cavalieri, y en el hecho de que éste último hubiera recibido más dibujos, todos ellos de una temática similar, como fueron La Caída de Faetón y El Castigo de Ticio.

Vistos los dibujos que Miguel Ángel regaló, además de la correspondencia que intercambió, hace muy creíble la teoría expuesta sobre el amor del genio por Cavalieri, aunque este hecho no se pueda probar y quede como suposición de autores contemporáneos. Ya Vasari, en su obra Vidas, dedicada a grandes maestros italianos del mundo del arte, quitó peso a esta interpretación de asuntos amorosos. Gran admirador como era de Miguel Ángel, argumentó que el objetivo de los dibujos no era otro que Cavalieri aprendiera a dibujar, repitiendo los modelos que el artista creaba exclusivamente para él. Y para formalizar esta teoría, según nos relata Ruvoldt, Vasari hizo hin-

\footnotetext{
${ }^{35}$ Son favorables a esta teoría entre otros, P. L. DE VECCHI, op. cit; P. PREISS, o.cit; M. WINNER, op. cit., p. 228.
}

capié en el hecho de que los protagonistas masculinos de la Caída de Faetón, Il Sogno, y el Castigo de Ticio se parecen considerablemente entre sí, son modelos que se repiten anatómicamente, aunque varíe el ángulo de la representación ${ }^{36}$.

Il Sogno muestra dos figuras predominantes, rodeadas de un halo de dibujos o esbozos secundarios, que forman una nebulosa circular en torno a la persona del joven desnudo. Éste se halla sentado en una caja rectangular, mirando hacia arriba, reclinado sobre una esfera, dejando entrever la inestabilidad de la misma. Su pierna izquierda se estira hasta tocar el suelo, mientras que la derecha se recoge y se posa en el rectángulo del que cuelga una tela o paño. En el interior del rectángulo se amontonan unas cuantas máscaras, barbudas e imberbes. El joven, que se gira sobre su tronco, parece centrar su atención en la llamada de la trompeta de la figura alada ${ }^{37}$ que desciende desde lo alto. Con la trompeta apuntada a la frente del joven, el ángel infla sus carrillos para que su sonido no deje indiferente a nadie, para que el joven protagonista despierte de su letargo, despierte asimismo su alma y con ella los pecados puedan desaparecer de las entrañas del sueño. Es la virtud quien clama con la trompeta. Entre ambas figuras establecen el eje vertical y la división de la composición en elementos a izquierda y derecha. Aún así, la ambigüedad de la figura, el que la acción representada no esté del todo definida, y el hecho de

\footnotetext{
${ }^{36}$ M. RuVOLDT, op. cit, p. p. 93-94.

${ }^{37}$ Es innegable que la parte superior de la composición la ocupa una figura alada. Winner defiende como cierta la teoría de que el hecho de que la figura portadora de la trompeta lleve alas significa que se trata de un espíritu. Parece que Tetius definió por primera vez la figura como ángel, aunque el apelativo de genio también sería válido. El hecho de decantarse por el primero o por el segundo quedaría en función de una interpretación dentro de un contexto cristiano para el ángel y un contexto más humanista y clásico para la palabra genio. M. WINNER, op. cit., p. 230.
} 
que el propio creador de la obra no dejara por escrito el significado de la misma, hace plantearse algunas preguntas. Winner se pregunta si el joven se está incorporando o reclinando, si se halla en el momento de asir el globo terráqueo o alejándose de él, si en verdad escucha el ruido de la trompeta del ángel, etc. Sea como fuere, hoy día se considera que en la obra Il Sogno la figura central alude al hombre, la mente y el alma humana.

A los lados del joven, se amontonan figuras dibujadas en forma de esbozo. Es muy interesante el que las dos figuras centrales estén trabajadas con mayor grado de definición y claridad, además de mayor tamaño y escala, destacando sobre todas las restantes. La circunferencia abocetada mediante rostros, cuerpos entrelazados y elementos varios, se mantiene a cierta distancia del eje principal gracias a que éstos no muestran igual juego de luces y sombras, carecen de esa grandeza volumétrica de la que hacen gala la virtud y el alma humana.

Si bien es cierto que el pintor de la capilla se basó en el grabado del florentino, se tomó ciertas licencias a la hora de la creación pictórica. Ante todo, cabría señalar que una de las mayores diferencias existentes entre ambas obras es la forma en que están tratadas las imágenes. Si con Miguel Ángel la definición del halo circundante es a modo de boceto, en Azpeitia, todas las figuras se tratan con la misma intensidad. En el primer caso, los esbozos existen mientras quien los crea e imagina se mantiene en un estado de dormitación, y en Azpeitia, el hecho de transmitir la idea del pecado hace que las imágenes ganen en corporeidad y consistencia.

Comencemos con la comparación entre ambas. En la parte inferior izquierda se representa la gula. El primer grupo del dibujo de Miguel Ángel se corresponde con los dos primeros grupos descritos en el caso de la Capilla de la Soledad. El personaje que sujeta el odre y el que se apoya en la mesa esperando el banquete, han modificado sus posiciones, pero se mantienen iguales. Sin embargo, el personaje que avivaba el fuego se desvanece en la capilla.

El segundo grupo de imágenes de $I l$ Sogno alude a la lujuria (Fig. 5). Es, con diferencia, el grupo que mayor espacio ocupa en comparación al resto de los pecados. Está formado por dos grupos de parejas captados en el momento de besarse. En la pareja situada más a la izquierda, la mujer se encuentra tumbada o reclinada, mientras que el hombre la sujeta con los brazos por el cuello. El segundo grupo representativo de la lujuria lo forman dos figuras que suponemos hombre y mujer, besándose con consentimiento mutuo. En Azpeitia, la representación de la lujuria está más simplificada en cuanto a número de figuras, aunque es más rotunda en su expresión, ya que se ejemplifica mediante el beso entre dos hombres. Es de subrayar que en el dibujo de Miguel Ángel aparecen hasta tres falos bien identificados, mientras que en el caso de las pinturas de Azpeitia, aquello que se describía como "cortinajes decorativos" no es sino un pene que un personaje sujeta con firmeza. Es un elemento visual más que sirve para enfatizar el carácter lujurioso de la escena, ya de por sí suficientemente remarcada. Si bien en algunos grabados posteriores los bocetos de los falos llegaron a desaparecer, lo cierto es que en Azpeitia se conserva, tal y como quiso Miguel Ángel en su obra.

El siguiente pecado en el dibujo del florentino es la avaricia. Es el pecado más sutilmente representado, y son pocos los elementos dibujados para tal fin. La avaricia son dos manos que surgen de entre la nada y sujetan una saca con dinero. En la capilla de Azpeitia este pecado no parece haber sido representado. 
Parece que la ira y la envidia en el grabado de Miguel Ángel, al igual que en Azpeitia, comparten espacio. La ira está claramente ilustrada en la figura del hombre que levanta su brazo con furia, sujetando a su víctima por la cabeza. Una tercera figura intenta separar al agresor y zanjar la disputa. En el caso de las grisallas de Elola, la ira se ha representado en forma de demonio cornudo. (Fig. 6)

La envidia está junto a la ira. Se ve muy esbozada y con menos definición que su vecina de espacio. Se trata de un hombre que tira de una capa, queriéndosela arrebatar al dueño de la misma. En Azpeitia se mantiene igual que en Il Sogno.

La pereza ocupa el espacio simétrico a la gula. Se compone de una figura agachada y medio adormilada, y justo encima, otra figura se despereza y lleva el brazo derecho hacia la nuca. En el caso de Azpeitia, es significativo el cambio que ha sufrido la imagen. Il Sogno muestra una figura sentada y encerrada en sí misma, y en Azpeitia, sorprendentemente, su lugar lo ocupa el hombre que porta una escalera ${ }^{38}$. (Fig. 7).

La parte hueca del rectángulo sobre el que se apoya la figura humana de Il Sogno, muestra máscaras en primer término, en contraposición a la pintura de Azpeitia, que ha optado por suprimirlas. Parece que significaran los malos pensamientos, las fachadas o elementos externos que al incorporarlos al rostro, nos desvirtúan. Pueden ser concebidas como atributos del sueño, como por ejemplo, la figura de La Noche de la Capilla de los Medici en Florencia. "Las diferentes máscaras que el hombre utiliza

\footnotetext{
${ }^{38}$ Imagen posiblemente alusiva a la escala de Jacob (Génesis 28, 11-19). La visión de la escala de Jacob por la que ascienden y descienden ángeles, también se sucede en un contexto de ensoñación, al igual que el tema de Il Sogno de Miguel Ángel. E igualmente hace alusión a la unión de los testamentos. SAN JERÓNIMO, op. cit., p. 35
}

para esconder su verdadero ser no son otra cosa que sus vicios, que deforman la verdadera imagen y semejanza del hombre con respecto a la verdad divina. La belleza desnuda del joven es la desenmascarada imagen de Dios" $^{\prime 39}$. Las máscaras ya en época romana servían para rememorar a los difuntos, y fueron tema recurrente en sepulcros y arte funerario en general. En Azpeitia se pudo suprimir este detalle ya que el mensaje era la prefiguración del vicio y los pecados, y la alegoría de la virtud, interpretación igualmente válida sin la presencia de las máscaras, que pudieran resultar de distracción.

Finalmente es conveniente tratar el tema del ángel alado. Antes de nada, hay que hacer hincapié en la situación física del ángel o genio en el dibujo de Miguel Ángel. Tal y como comenta Winner, "la trompeta penetra el círculo nebuloso de los pecados capitales, mientras que su cuerpo, visto de espaldas, se mantiene en la zona celestial, más clara que la nebulosa de vicios" ${ }^{\prime 40}$. Algo parecido pasa en las pinturas de Azpeitia. Los ángeles (en la capilla guipuzcoana la figura del ángel se duplica para colocarse simétricamente con respecto a la ventana circular), se sitúan justo debajo de la Visión de Ezequiel, es decir, en la parte celestial. Sin embargo, y para no perder el vínculo con el grabado, la trompeta rompe con el marco que encuadra la composición inferior, y enlaza con la zona donde se arremolinan los vicios, pecados, e incluso el alma humana. Se entiende así, que los ángeles de Azpeitia están inspirados de este mismo grabado (Fig. 8). El ángel que Miguel Ángel ideó como la supuesta representación de la virtud, se duplicó en la capilla, para que dichos ángeles se pudieran, además, considerar los mensajeros de la llegada del Juicio. Hay que tener en cuenta que en la vi-

\footnotetext{
${ }^{39}$ M. WINNER, op. cit., p. 233.

${ }^{40}$ Ibídem, p. 229.
} 
sión de Ezequiel de Holbein, no se planteaba ninguna composición en la que aparecieran ángeles y que para la fecha, la Capilla Sixtina de Roma se hallaba finalizada, con sus consabidos grupos de ángeles trompeteros. Así, el ángel de Il Sogno se desdobla por composición y "convierte" la idea del Juicio de Ezequiel en un Juicio Universal.

Pero además, existe una diferencia significativa entre grabado y pintura. En el grabado original, la trompeta del ángel se apoya directamente sobre la frente del joven. Panofsky entendió la trompeta como la fama que "despierta la mente de los virtuosos, los despierta y despabila del adormecimiento o sueño ligero de la pereza y ociosidad, y hace que se mantengan despiertas en permanente vigilia" ${ }^{41}$. En referencia a este tema, existen grabados que tratan sobre Dios Padre y la creación y animación de la vida humana mediante la exhalación de su aliento ${ }^{42}$. Enlazando estas ideas con el concepto neoplatónico que regía la vida y obra de Miguel Ángel, se recoge finalmente un soneto que dirigiera el genio florentino a Tommaso Cavalieri:"Para retornar a donde viene / la forma inmortal baja a la cárcel terrenal / viene como un ángel de piedad / que salva a todo intelecto y honra al mundo" ${ }^{\prime 3}$. En Il Sogno el ángel alado se encuentra en el proceso de descender al mundo terrenal para salvar la figura desnuda que, no escondiéndose tras ninguna máscara, mantiene su semejanza con la imagen de Dios.

De esta manera, el mensaje global de la pared sur trata sobre la llegada del Juicio y la necesidad de una vida virtuosa alejada de los vicios y pecados. Pero también existe alguna interpretación más subjetiva del mensaje del dibujo. Ruvoldt propone la

${ }^{41}$ WINNER, M.: op. cit., p. 233.

${ }^{42}$ Ibídem, p. 239.

${ }^{43}$ Ibídem, p. 238. obra "como ejercicio de meditación de significado ilimitado que nos lleva a volver una y otra vez a la contemplación de la misma (...) un programa más complejo que alude a la melancolía, sueños, amor, deseo y creación"44. Esta asimilación de Il Sogno con la melancolía parte de la consideración que de los melancólicos se tenía. Las personas "aquejadas" por la enfermedad o el temperamento melancólico, sufrían de caracteres indisolublemente unidos a los actos más viles y pecaminosos. Se consideraba que los melancólicos eran gente avara y tacaña, enriquecidos incluso por medios deshonestos, lo que era "síntoma de avaritiosa melancolía"45. Eran considerados en esencia callados, tristes, lujuriosos, inestables, irascibles, envidiosos, propensos a la gula, y perezosos entre otras "cualidades". Es decir, se les consideraba todo aquello que Miguel Ángel enumeró y dibujó en Il Sogno: gula, lujuria, ira, envidia, avaricia y pereza, a excepción de la soberbia (pecado que falta en el grabado). Como colofón, se pensaba que los melancólicos eran personas que despreciaban el sexo opuesto, lo que justificaría la presencia de la homosexualidad en el caso de Azpeitia.

\section{VARIACIONES E INTERPRETA- CIONES DEL GRABADO DE MI- GUEL ÁNGEL}

Existen diversas variaciones realizadas a partir del dibujo original de Miguel Ángel. Ruvoldt cuenta al menos 11 copias del dibujo original ${ }^{46}$ (ninguna totalmente fiel al mismo), sin contar la Capilla de la Soledad. Ya en 1537 Battista Franco pinta su batalla de Montemurlo, obra en la que se reconocen fácilmente las figuras del joven

\footnotetext{
${ }^{44}$ M. RUVOLDT, op. cit., p. 86.

${ }^{45}$ R. KLIBANSKY, E. PANOFSKY \& F. SAXL, Saturno $y$ la melancolía, Madrid, 1991, p. p. 279-280.

${ }^{46}$ En el artículo de Ruvoldt se recogen los grabados pertenecientes a las obras de B. Franco, M. Venusti, N. Beatrizet y A. Allori.
} 
de Il Sogno. Marcelo Venusti, realiza una obra igualmente titulada Il Sogno, en 1540. Copia del original del florentino, guarda un parecido extremo, a excepción de las figuras pertenecientes al grupo de la lujuria. El grabado de Nicolas Beatrizet ${ }^{47}$ es quizá el más importante con respecto a los que se enumeran. Ruvoldt sitúa hacia 1545 la copia que actualmente se conserva en el British Museum. Pero existe además una copia de este grabado en la Real Colección de Estampas de San Lorenzo de El Escorial que González de Zárate recoge bajo el título "Sueño de la vida humana" ${ }^{48}$ (es esta la fuente gráfica que primero se localizó en el curso de la investigación). No consta la información referente a la datación de este grabado. Los dos grabados difieren en que la versión de El Escorial, además del texto "MICHAEL ANGELUS IN. VEN." lleva escrito "Ant. Sal. Exc." (Fig. 9). Son obras que guardan total fidelidad al original a excepción de que las figuras del halo circundante, han sido trabajadas con la misma intensidad que las figuras principales, co-

\footnotetext{
${ }^{47}$ Nicolás Beatrizet, artista de origen francés, trabajó entre 1540 y 1562 en Roma. Comenzó siguiendo el estilo de Marcantonio Raimondi, aunque pronto abandonaría estas tendencias para realizar copias de trabajos de Miguel Ángel. Entre las copias, se encuentran además los citados Castigo de Ticio y la Caída de Faetón. Divulgó, por tanto, dibujos y pinturas de la época, lo que lo convierte en transmisor de las corrientes artísticas y las tendencias renacentistas italianas. J. M. GONZÁlez DE ZÁRATE, Real colección de estampas de San Lorenzo de El Escorial, Madrid, 1992-1996, Vol. I, p. p. 113-114.

48 J. M.GONZÁlez de ZÁRATe, Real colección..., p. 128. Hay que añadir que este mismo grabado también se encuentra en el Instituto Nazionale per la Grafica de Roma, stampa FC71126, volume 44H22. El título de "Sueño de la vida humana" se recoge además en la obra de E. BOREA, Lo specchio dell'arte italiana. Stampe in cinque secoli, Pisa, 2009. Menciona la obra y sus posteriores copias bajo los títulos de "El sueño de la vida" o "El sueño de la humanidad" (Volumen IV, p. 124-126). Atendiendo a lo complejo del mensaje transmitido por el grabado, dichos títulos son totalmente adecuados e incluso cabría decir, más convenientes para la obra.
}

brando todos los personajes del grabado similar importancia.

Entre 1579 y 1580, Alessandro Allori pinta de nuevo Il Sogno. Una réplica casi idéntica la recoge Battistini en el capítulo dedicado al Sueño ${ }^{49}$. Nombra la obra con el título El Sueño, y en el apartado de la autoría simplemente señala que se trata de un artista del siglo XVI. Por último, existe una estampa procedente del Instituto Nazionale per la Grafica de Roma. Este grabado difiere en que no tratándose de una matriz, la obra en su conjunto es un espejo de las hasta ahora mencionadas (Fig. 10).

\section{GRABADOS, UNA APORTACIÓN FUNDAMENTAL A LA ICONO- GRAFÍA Y SIGNIFICADO DE LA OBRA}

Los grabados de la Visión de Ezequiel de Hans Holbein el Joven e Il Sogno de Miguel Ángel son una aportación fundamental sobre la difusión de los grabados y la lectura iconográfica de las pinturas murales de Guipúzcoa. Son el más claro exponente de la asimilación de grabados nórdicos e italianos en Guipúzcoa, y de la enorme influencia y repercusión que éstos tuvieron en la temática y la iconografía de la época. El primero, de origen alemán, y el segundo de origen italiano, son muestra del equilibrio de dos corrientes artísticas, dos formas de interpretar el arte, que si bien se originaron en puntos alejados entre sí, confluyeron en armonía en el arte español, dejando obras de grandísima calidad, como es el caso de Azpeitia. Es ciertamente importante el hecho de haber identificado correctamente los documentos gráficos en los que se basan las grisallas del paño sur, para comprender en su justa medida el alcance y la trascendencia que dichos grabados tuvieron en el País Vasco. En Guipúzcoa, a falta de

\footnotetext{
${ }^{49}$ M. BATTISTINI, op. cit., p. 232-235.
} 
obras similares y de tamaña complejidad, el grupo iconográfico y gráfico en sí de las grisallas junto al conocimiento de su origen compositivo hace de las mismas un conjunto único, y actualmente, el grupo de mayor interés iconográfico.

A la hora de realizar la interpretación del lienzo sur, hay que partir de la premisa de que se trata de dos grabados de autores distintos, cada cual con su significación, que han sido adecuados el uno al otro, transmitiendo en última instancia un sólo mensaje. Tanto la Visión de Ezequiel como Il Sogno han sido trabajadas y evolucionadas en el tiempo y sus mensajes han servido de base a diversas variaciones compositivas. Sin embargo, en este caso concreto, ambos grabados han modificado ligeramente su mensajes (y en el caso de Il Sogno, también su composición), de forma que se ha hecho posible una lectura conjunta y un mensaje unificado.

La Visión de Ezequiel expresa el juicio y las consecuencias que sobrevendrán a la humanidad por la idolatría y el paganis$\mathrm{mo}^{50}$. Il Sogno de Miguel Ángel nos permite contemplar un mosaico de vicios y pecados que rodean al alma humana, y que son los protagonistas del halo que envuelve la escena principal. El ángel alado es el encargado de despertar la conciencia humana. Debemos entender que el paño sur en su totalidad nos relata un juicio, que si bien parte de un Juicio individual, se universaliza por el mensaje de Il Sogno. El hecho de

${ }^{50}$ J. Helvella váZQUEZ, op. cit, p. 42; R. W. KLEIN, The prophete Ezekiel and his message, Columbia, South Carolina, 1988, p.p 10-11; J. LAMELAS, “La visión del Templo y la Gloria de Dios (Ez. 40-48)", Reseña Bíblica, Ezequiel, no 52, Estella, 2006, p. 39; J. STEINMANN, Le prophète Ezéchiel et les débuts de l'exil, Paris, 1953, capítulos IV y XI. Si las visiones de Ezequiel encierran principalmente un mensaje del juicio sobrevenido como consecuencia del pecado, también guardan la idea de la esperanza de un nuevo día en el que Dios se haga presente en la tierra. que el ángel trompetero se haya duplicado con respecto al grabado original (y que se separen de la vida mortal y se ubiquen en la parte celestial de la composición), acerca posiciones respecto a los ángeles trompeteros del Juicio Final de la Capilla Sixtina. Y si Il Sogno hizo referencia a los sentimientos de Miguel Ángel, su reinterpretación reconvirtió su significado en un mensaje moralizante.

El hecho de que el mensaje gire continuamente sobre el eje de la moral, la virtud, el juicio y el pecado, da una clara referencia sobre la figura del comitente. A sabiendas de que fue hombre de acción y capitán en la conquista del Perú, su capilla y su recinto funerario dejan de lado casi por completo ese aspecto (a excepción de la figura yacente del indiano tocado con vestiduras militares y la grisalla de los lanceros en la pared norte), para centrarse únicamente en la parte moralizante de las pinturas. Fueron muchos y variados los motivos que impulsaron a gentes como Elola a la búsqueda de una nueva vida en "las Américas", pero los cánones humanistas abogaron por representar casi exclusivamente el virtuosismo y la justicia que habrían de ser las más sabias consejeras de nobles y príncipes renacentistas. Lo mismo sucede con capillas funerarias coetáneas, incluso en la cercana Universidad renacentista de Oñate.

Aunque, como se ha dicho, el propio Elola únicamente dispuso por escrito el lugar de enterramiento y la obligatoriedad de la construcción de su recinto funerario, es de una gran notoriedad que los albaceas de su testamento crearan todo un ideario medido a las exigencias tanto de la moralidad renacentista como de la importancia de la figura del de Azpeitia. Para afrontar el trance del juicio, es necesaria la lectura de la Visión de Ezequiel y de Il Sogno, ambas respaldadas por la caridad y las virtudes. La muerte, segura para todos, se convierte para Elola en el primer paso hacia el des- 
pertar a una vida de perfección. La empresa de Elola queda materializada en la capilla mediante diferentes escenas de su vida, sus victorias en Perú, su figura con esfera y compás (muestra con orgullo sus aportaciones al conocimiento de la tierra y del nuevo mundo, aportaciones que hacen que el Orbis Terrae se convierta ya en el siglo XVI en un hecho consumado), el crucifijo al que ofrece sus victorias (la cristianización tiene un hueco en la capilla, ya que se pudo esgrimir tal objetivo en la conquista), y unas cuantas esferas diseminadas por todo el interior de la capilla. Su empresa tiene cariz universal. Y Elola es el adalid de la caballerosidad, la universalidad y el vir- tuosismo llevados al extremo.

Así, desde el momento en que un personaje adinerado decide construirse un sepulcro en su propia capilla exenta (al alcance de unos pocos), el concepto que se transmite enlaza la idea de la muerte con la idea de la virtud del donante y perduración de un apellido y una memoria. La Capilla de la Soledad es el resumen de una de las ambiciones del Renacimiento, una muestra del poder de un hombre de su tiempo que asume los ideales de la fama perdurable y que traduce sus riquezas materiales en una obra arquitectónica, escultórica y pictórica, digna representante de los ideales humanistas del XVI.

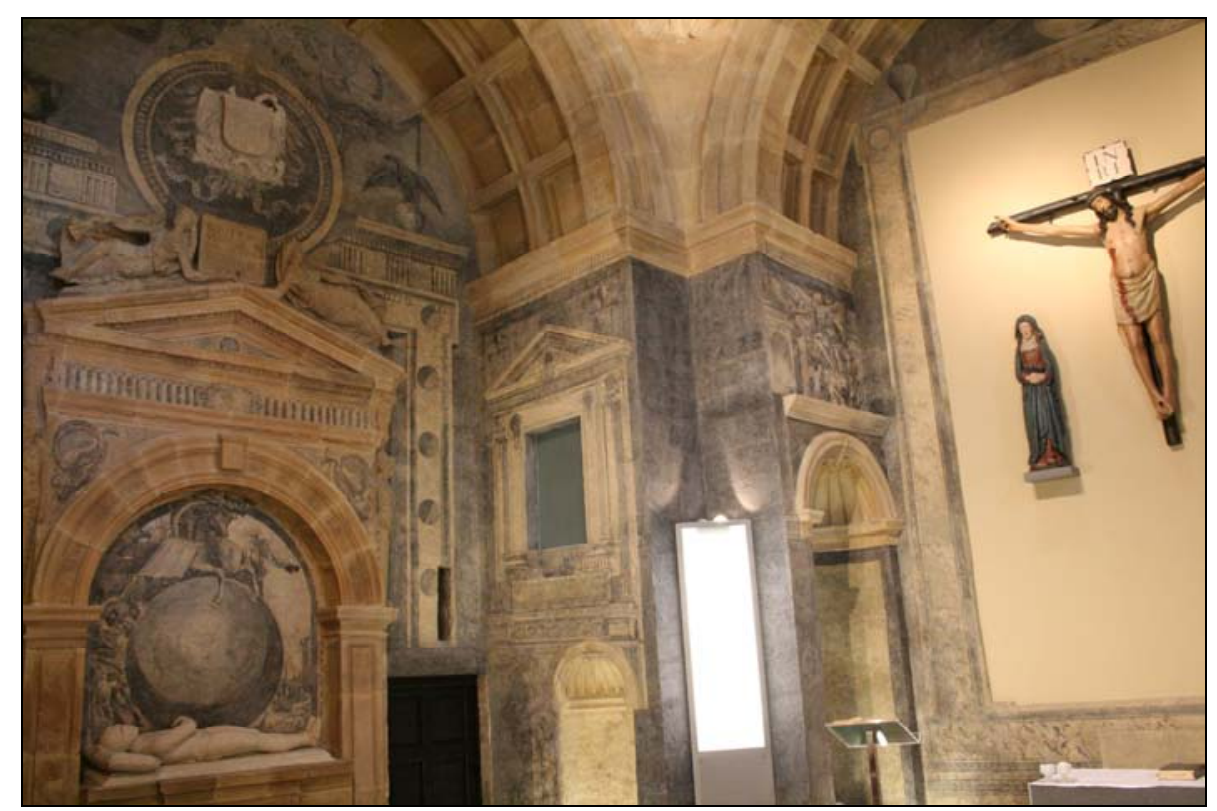

- Fig. 1. Lienzo Norte con el monumento funerario de Nicolás Saez de Elola en primer término. A la derecha, el calvario que preside el lienzo este. 


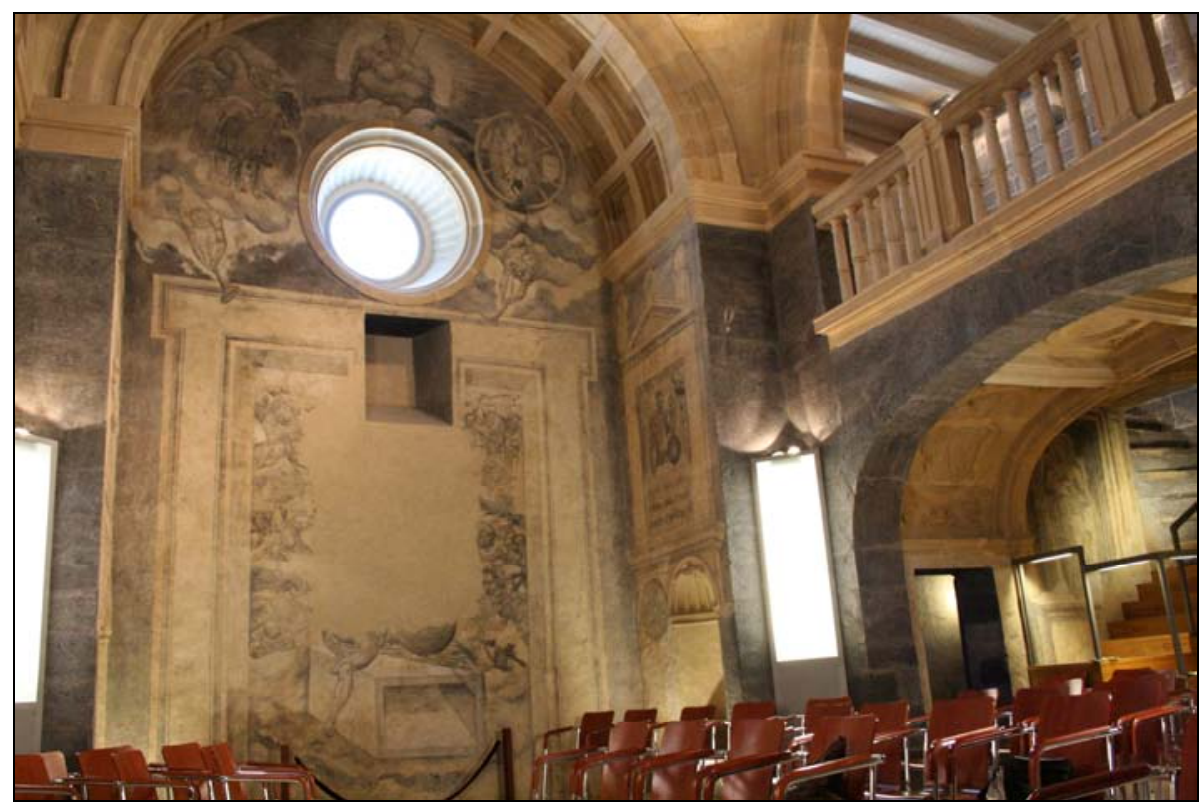

- Fig. 2. Lienzo Sur. Capilla de la Soledad. A la derecha se aprecia el bajo coro y las escaleras que conducen al alto coro, presididas por la imagen de Virgen y el Niño.

E $Z$ ECH IEL I $S$ quatuor animalium, rotarum, throni \& imaginis fuper thronum uifiones.

\section{E Z E C H. I.}

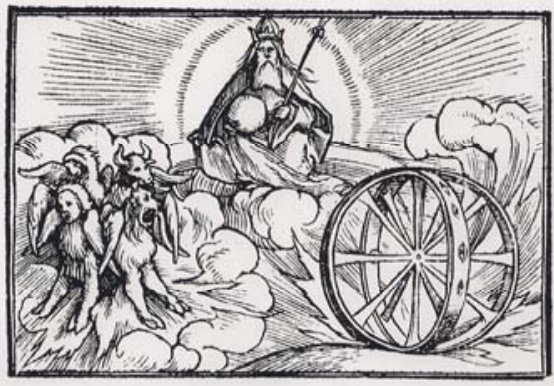

Animales muy temidos Vio en vifion Ezecbiel De vn carro muy aßidos $\mathrm{Y}$ cerca el trono metidos Donde efta Dios de I fraël.

- Fig. 3. Visión de Ezequiel. Hans HolbeIN EL Joven. Imágenes del Antiguo Testamento, Illes Balears, 2001

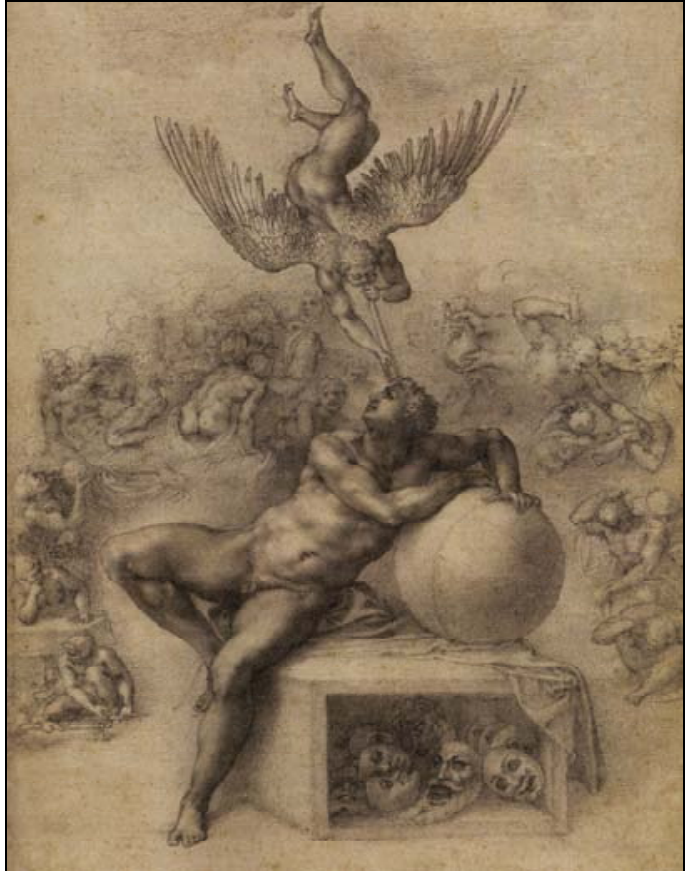

- Fig. 4. Il Sogno o Studio per Il Sogno, P.L. DE VECCHI, Michelangelo Pittore, Milan, 1984. 

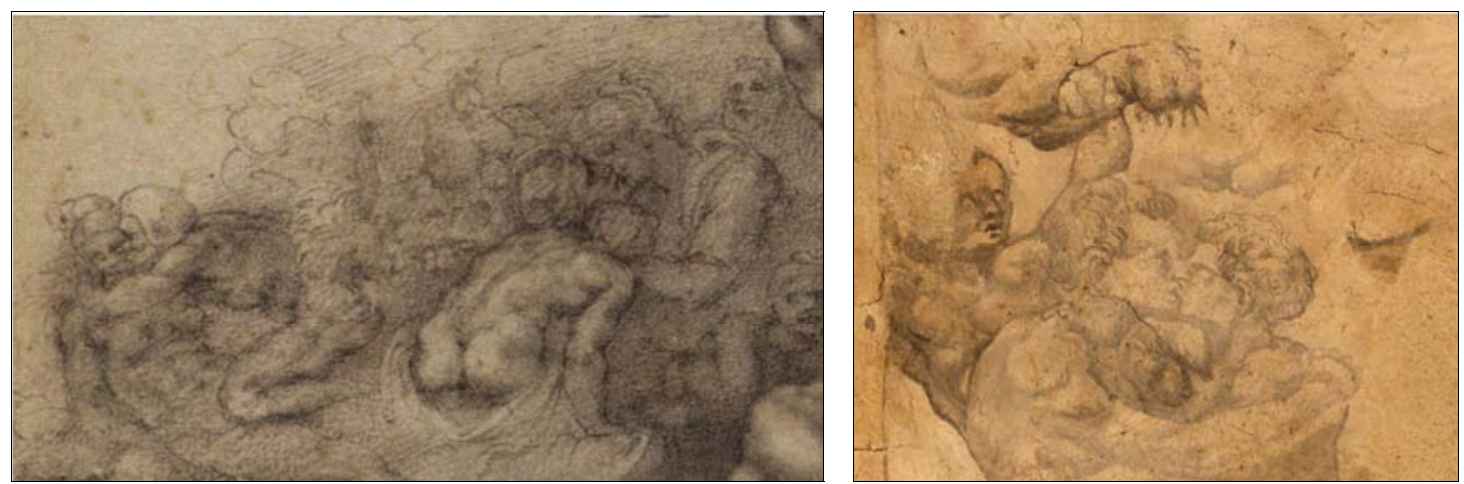

- Fig. 5. Detalle de la lujuria. Izda Il Sogno de Miguel Ángel. Dcha, Capilla de la Soledad.
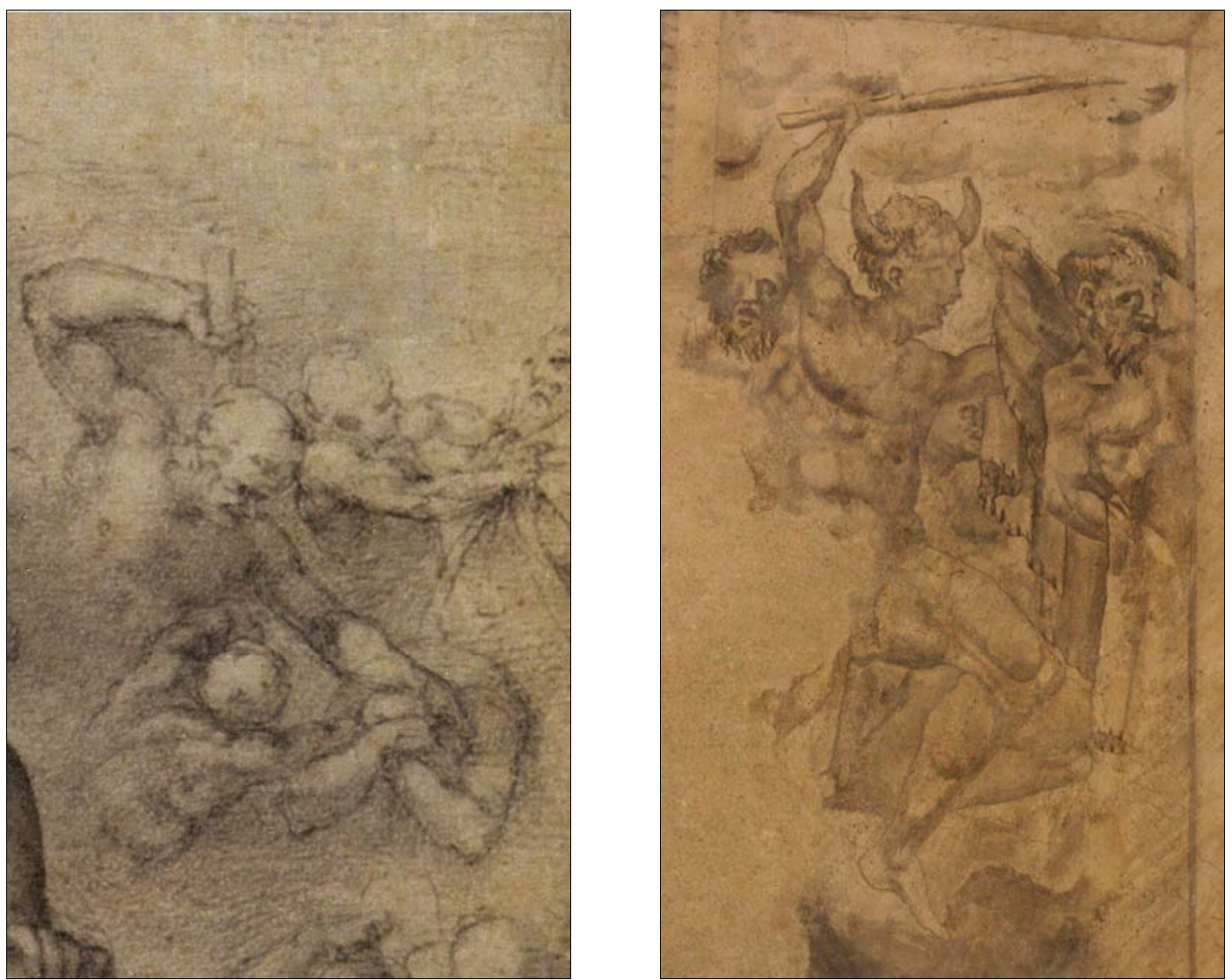

- Fig. 6. Detalle de la ira y la envidia. Izquierda, Il Sogno de Miguel Ángel, derecha, Capilla de la Soledad. 

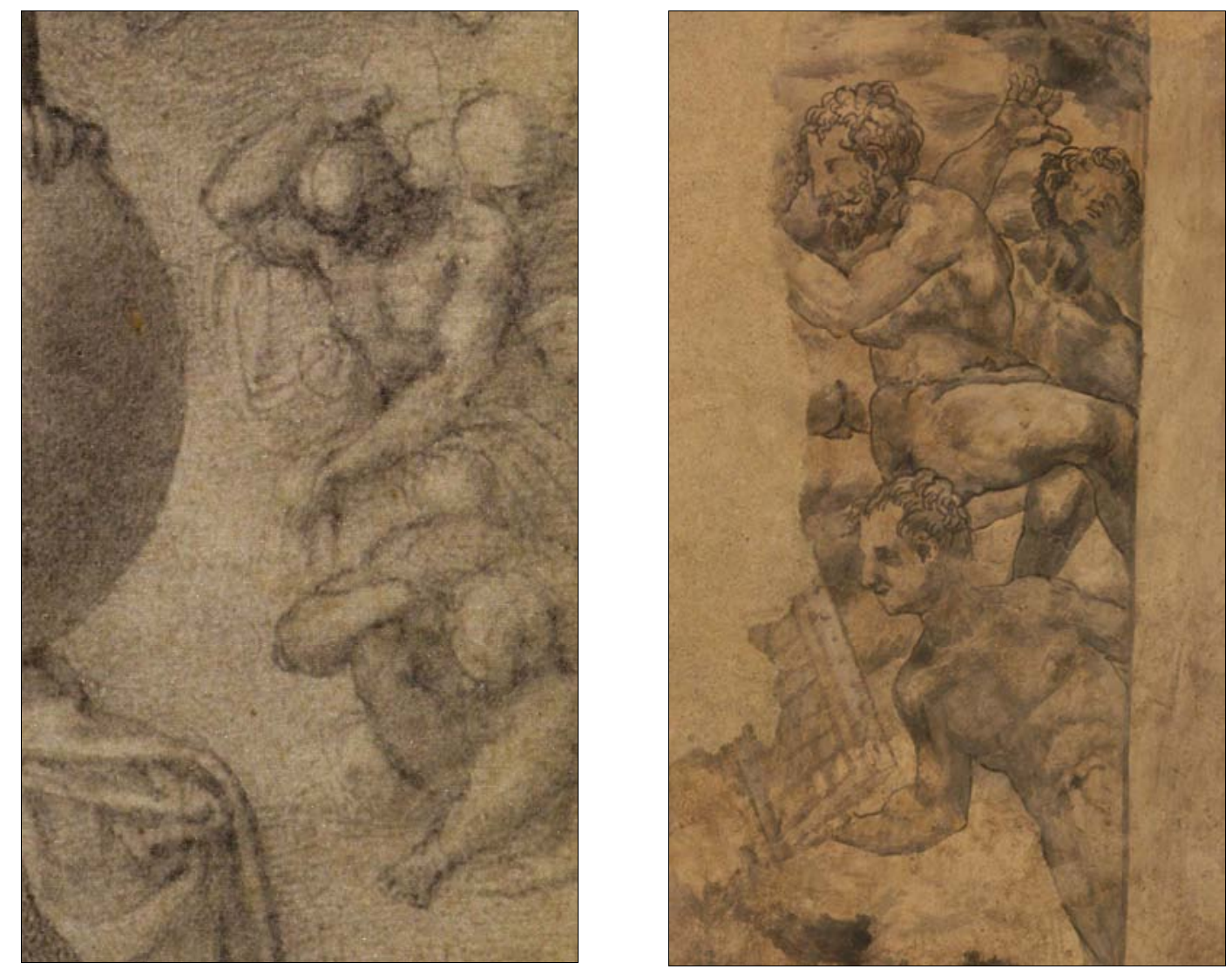

- Fig. 7. Detalle de la pereza. Izquierda, Il Sogno de Miguel Ángel, derecha, Capilla de la Soledad
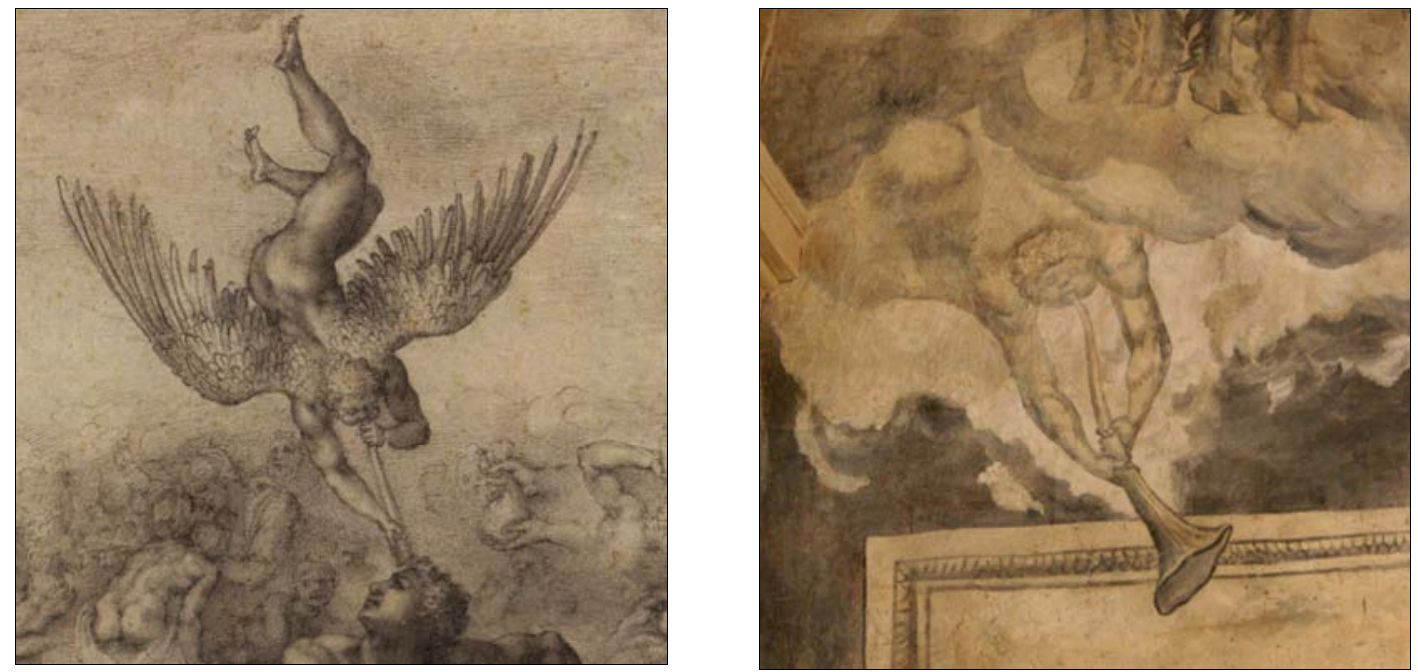

- Fig. 8. Detalle del ángel. Izquierda, Il Sogno de Miguel Ángel, derecha, Capilla de la Soledad. En la Capilla de Azpeitia, el ángel aparece duplicado, mientras que en el dibujo de Miguel Ángel el ángel y la trompeta se localizaban tocando la frente de la figura humana. 


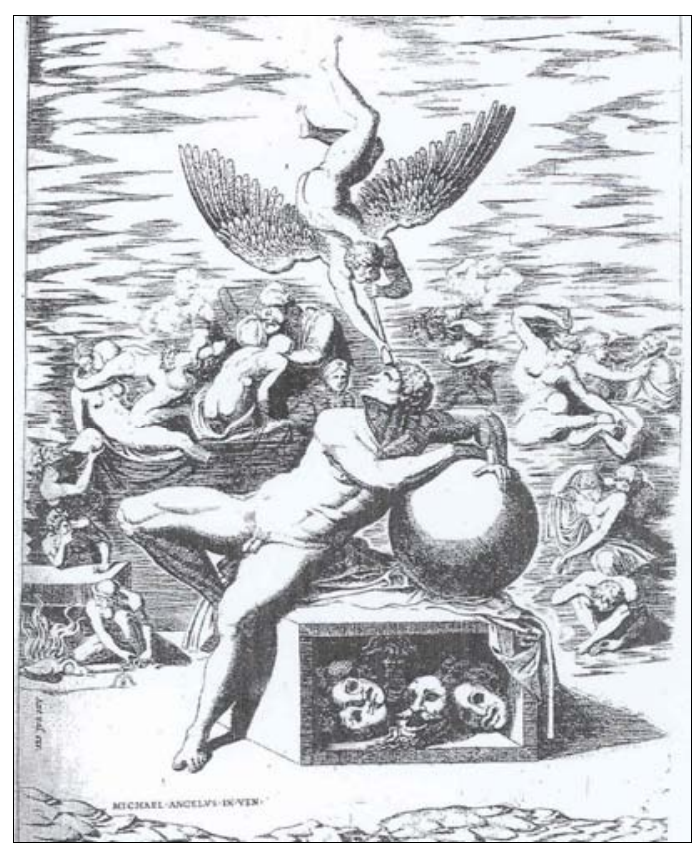

- Fig. 9. "El Sueño de la vida humana". Nicolás Beatrizet. J. M.GONZÁLEZ DE ZÁRATE, Real colección de estampas de San Lorenzo de El Escorial, Madrid, 1992-1996, Vol. I, p. 128.

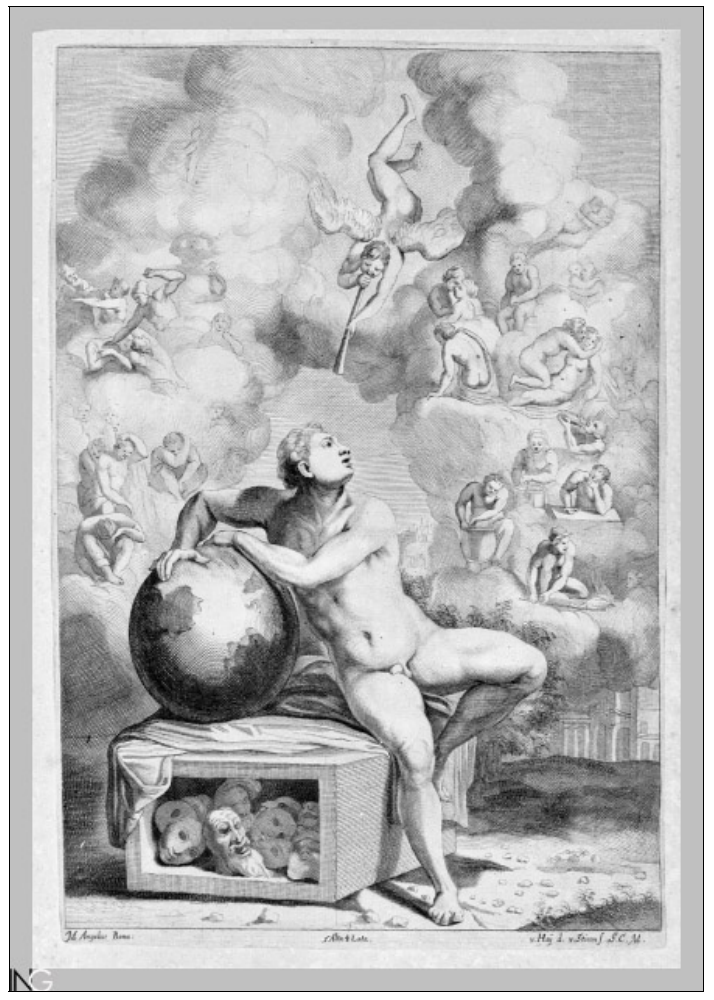

- Fig. 10. Il Sogno. Instituto Nazionale per la Grafica de Roma, stampa FC23442, volume 32H11. 